\title{
5 Political economy of climate and energy policies in the United Kingdom
}

\author{
Nora Stognief, Paula Walk, and Pao-Yu Oei
}

\section{Introduction}

The United Kingdom (UK) announced in 2015 that it would phase out coal power generation entirely by 2025 and has recently brought forward the date to 2024 (BEIS, 2020b; Littlecott et al., 2018; Rudd, 2015). Meanwhile, despite being the most climate-damaging energy carrier, coal is experiencing a renaissance in many other countries across the world where new coal capacities are still being built (Steckel et al., 2015). What rationales are shaping these major differences in the development of coal? In developing the AOC ('Actors, Objectives, Context') framework, covered in Chapter 1, Jakob et al. (2020) argue that climate and energy policies are influenced not only by economic or strategic factors but also by political economy factors. The UK is one of the phase-out countries, along with Chile, Germany, Bulgaria, and the United States. Insights on what political economy factors led to the UK's transition away from coal might help guide similar transitions in other countries.

In order to identify the objectives, actors, and contextual factors relevant to the UK coal phase-out in the study period 2000-2020, 22 stakeholders were interviewed between 27 May and 1 October 2020. They were mainly identified by means of a literature review and internet research. Special attention was directed to having all relevant stakeholder groups represented. We interviewed eight policymakers (p), seven researchers (r), five societal actors (s), and two business actors (b). We further applied a 'snowballing' principle, meaning that, at the end of every interview, we asked interviewees whether they could recommend further experts for us to talk to. A full list of interviewees is provided in online Appendix A.2. The cited number codes for the interviews do not correspond to the order in which the interviews are listed in the online appendix, so that statements cannot be linked back to a specific interviewee. The interviews were conducted using a semi-structured approach, following the interview guideline in online Appendix A.3. The answers were evaluated according to the AOC Framework to identify actors, context factors, and objectives that are relevant to the political economy of coal (Jakob et al., 2020). The results are intended to inform subsequent comparative analyses of different case-study countries. 
The remainder of this chapter is structured as follows. The "Country context" section gives some country context on UK energy policy and the coal phase-out process. In the "Political economy determinants of the coal phaseout" section, we present our results, namely the three main objectives we identified. We then structure the relevant contextual factors along with those objectives. The "Discussion" section then discusses the policy implications for the further energy transition in the UK as well as lessons learned relevant to other countries. The "Conclusions and outlook" section concludes.

\section{Country context}

The UK is a high-income country, a member of the G7 and the Organization for Economic Co-operation and Development (OECD), and the world's fifth largest economy by nominal GDP. It was a member of the European Union (EU) until 31 January 2020. Historically, the UK had a strong coal industry (Littlecott, 2015). Coal was the most important energy fuel until the late 1960s, when domestic coal mining had already started to decline after peaking in 1952 (Michaels, 2016). The 1984-1985 period was a major turning point as Margaret Thatcher's Conservative government announced a large number of pit closures, which led to the miner's strikes and subsequent destruction of union power (Phillips, 2014). The UK's domestic coal mining industry has remained relatively small ever since, with most of the coal used for electricity generation being sourced from abroad (Michaels, 2016). In the late 1990s, the privatization of the British electricity sector followed, which is now dominated by the socalled Big Six suppliers (British Gas, EDF Energy, E.ON UK, Npower, Scottish Power, and SSE). The government department that is responsible for energy is the Department for Business, Energy and Industrial Strategy (BEIS). Climate change is also one of the areas of responsibility of BEIS.

Following the coal phase-out announcement in 2015, the share of coal in the UK electricity mix has experienced a sharp decline (see Figure 5.1). Meanwhile, the deployment not only of wind (mainly offshore) and solar but also of natural gas has increased, accompanied by a decrease in electricity demand (BEIS, 2020c). From 2000 to 2014, coal's share varied between 27\% and 39\%, falling rapidly from 2015 after the coal phase-out was announced. In 2019 , the share of coal in the electricity mix was at only $2 \%$ (own calculations based on BEIS, 2021a). As of 2021, there are only four coal-fired power stations left in the UK, three of which are planning to convert or shut down before 2024 (Evans, 2021). ${ }^{1}$

Figure 5.2 gives an overview of relevant policies and events surrounding the coal phase-out in the study period 2000-2020, as well as selected prior developments that are relevant for contextual understanding. We briefly review which policies contributed to a reduction in coal-fired power generation before the coal phase-out was officially announced in 2015 .

Climate change has been an important political issue since the early 2000 s. However, the first pressures on UK coal power stations were exerted not by 


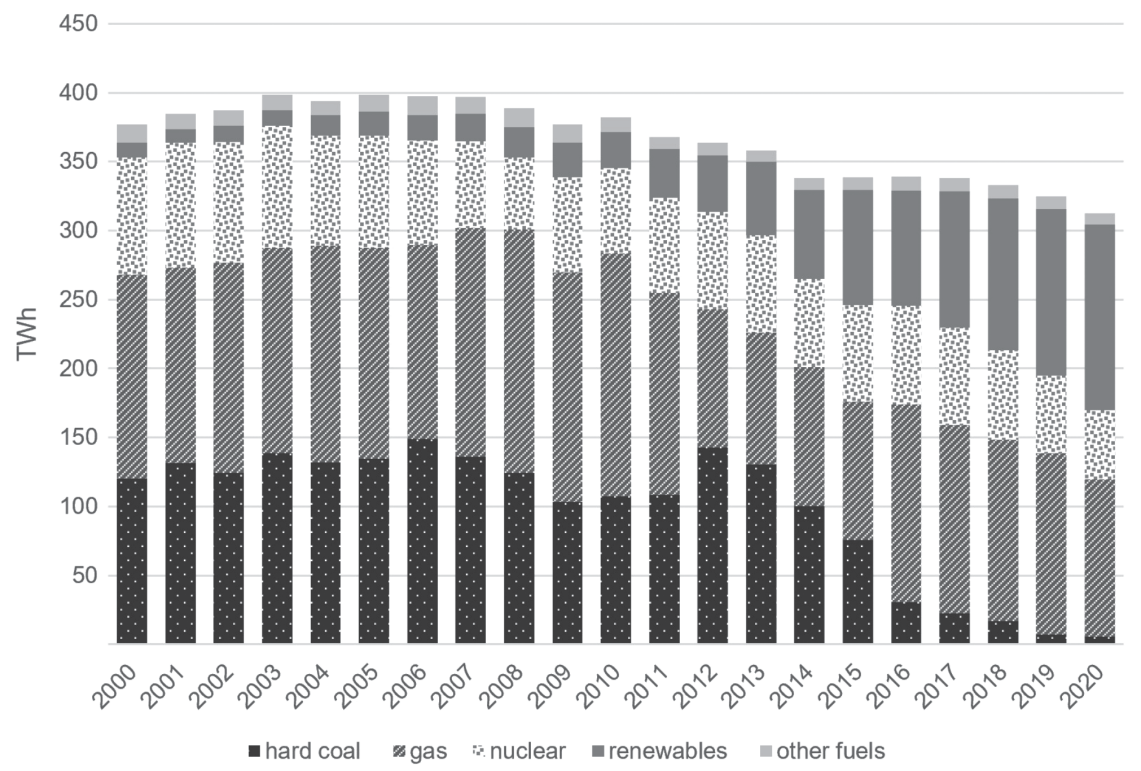

Figure 5.1 Gross electricity generation for the UK.

Source: Brauers et al. (2020) based on data from BEIS (2021a), modified.

domestic energy or climate policy but by EU air-pollution policy in the form of the Large Combustion Plant Directive (LCPD) (Isoaho \& Markard, 2020). The Climate Change Act, legislated in 2008, introduced a target of $80 \%$ of greenhouse gas (GHG) emissions reduction by 2050, which put further pressure on coal. In 2013, the Electricity Market Reform (EMR) introduced most prominently the capacity market (CM) in which capacities are auctioned. Also part of the EMR was the UK carbon price floor, which was introduced as a response to the low level of the EU carbon price within the EU Emissions Trading Scheme (EU-ETS). The UK carbon price floor ensured that the price of the EU-ETS did not fall below that pre-specified level. While the floor price has not increased as high as originally planned, it has created a significant additional cost for fossil-fueled power generators (Littlecott et al., 2018). This facilitated a strong growth in the deployment of renewable energy (RE) for electricity generation and the carbon price was a major factor in shifting the economics away from coal (Grubb \& Newbery, 2018). The CM, however, was still accessible to coal even after 2015 and thereby provides indirect subsidies which are estimated at an annual €138.4 million for the 2017-2020 period (van der Burg, 2017).

Isoaho and Markard (2020) point out that starting from 2013, the coal decline had already progressed to an extent that perspectives for future coal use had largely been driven out of the public discourse. This was partly because Carbon Capture and Storage (CCS) had ceased to be a viable option and was 


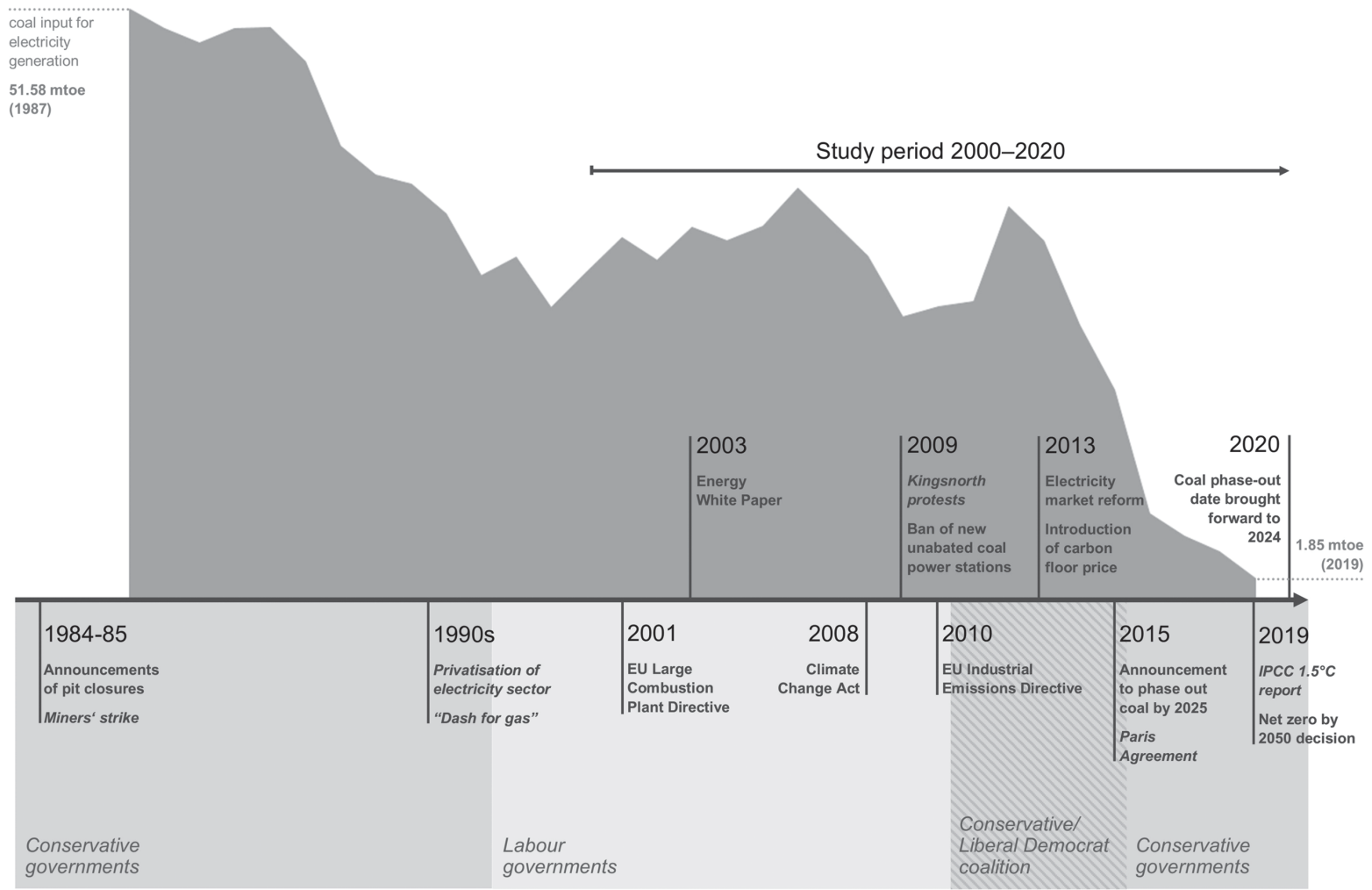

Figure 5.2 Timeline of policies and events surrounding the UK coal phase-out. Source: Own depiction with data from BEIS (2020c). 
abandoned by the government in 2015. In the run-up to the Paris Agreement that same year, the UK government officially announced that it would phase out coal by 2025 .

Brauers et al. (2020) identify the following determinants for the UK coal phase-out: the liberal market economy, policies such as the carbon price floor and EU emission standards, old coal infrastructure and weakened influence of unions, increasing costs for domestic coal with simultaneous availability of domestic natural gas and advances in RE, as well as NGO campaigns. They find that the UK coal industry has employed external as well as internal strategies to cope with the increasing pressures by climate policies and regulations. External strategies include successful lobbying for the CM and a cap on the carbon price floor, the establishment of narratives surrounding rising electricity prices and the possibility of blackouts. Meanwhile, as an internal strategy, generators have increased their investments in RE and natural gas in order to be less dependent on coal. According to Geels et al. (2016), incumbent actors play a major role in the UK's low-carbon transformation pathway, as structural reasons make the deployment of RE technologies by new entrants more difficult.

\section{Political economy determinants of the coal phase-out}

The 22 interviews as well as a supporting literature review yielded the list of societal and political actors and contextual factors given in Table A5.1 in Appendix A.1.The objectives mentioned by our interviewees are summarized into three high-level objectives: (1) climate action, (2) low electricity prices and jobs in the power sector, and (3) security of supply. Each high-level objective is presented in more detail in a subsection along with relevant contextual factors.

Figure 5.3 depicts the share of interviewees in each stakeholder group (business, policymakers, researchers, and societal actors; cf. Table A5.2 in Appendix A.2) who mentioned each of the three high-level objectives (or parts thereof, cf. Table A5.1 in Appendix A.1) to have influenced energy decisions in the UK. We merely identified whether or not an objective was mentioned by each interviewee but did not count how many times it was mentioned in each of the interviews. Mentions of objectives or contextual factors cited in this chapter not only necessarily reflect the opinion of the cited interviewee but also include mentions of the aspect being the priority of other actors.

As shown in Figure 5.3, 'climate action' was the only high-level objective mentioned by all 22 interviewees, closely followed by 'low electricity prices and jobs in the power sector', which was indicated in 20 interviews. 'Security of supply' was an objective that was mentioned less by societal actors than other actor groups. It must be noted, however, that our sample of business interviews consists of only two interviews and is therefore too small to be representative. In the following, we present the three high-level objectives together with relevant contextual factors. 


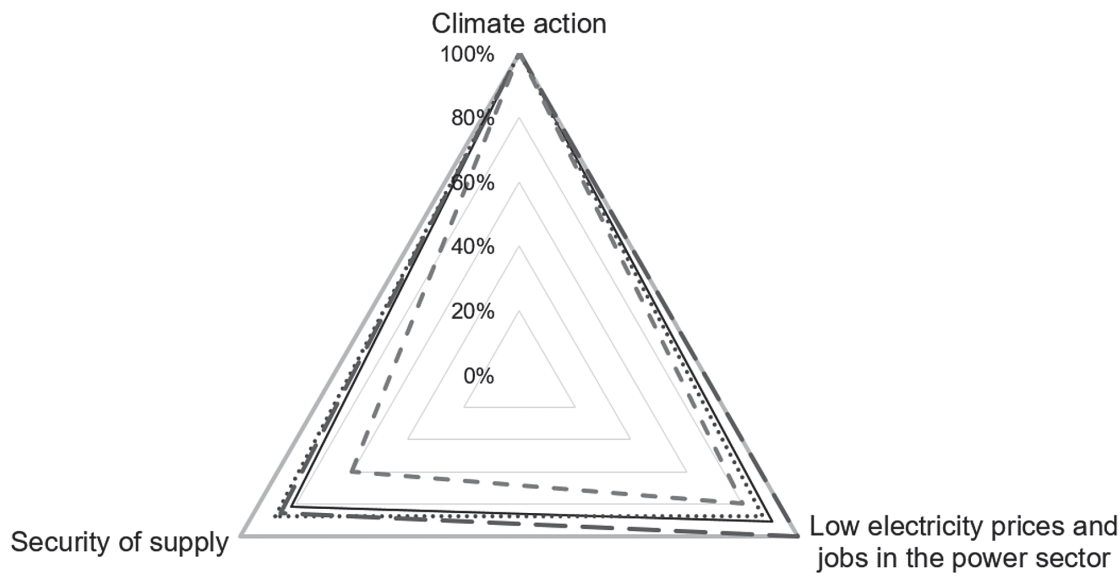

— all $\quad$ business $\quad . .$. ... policymakers $\quad$ - researchers $\quad$ - - societal actors

Figure 5.3 Objectives influencing the UK coal phase-out as shares of interviewees by category mentioning the respective objective. ${ }^{2}$

\section{Climate action}

A strong consensus on climate action emerged as one of the defining characteristics of the coal-phase-out situation in the UK. Climate change is now almost universally recognized as an issue that requires attention. All interviewees mentioned this high-level objective [r5, s1, s2, s3] or one or more of its sub-objectives. The sub-objective that came up most frequently was decarbonization of power or energy [b1, b2, p3, p4, p6, p7, r2, r3, r6, r7, s1, s2, s4]. A large number of interviewees also mentioned the broader objective of GHG emissions reduction, for instance in order to reach national climate targets [b1, p1, p2, p8, r2, r4, s1, s2, s5]. Another aspect is the transition directly to $100 \%$ clean power, hence not building new gas or using other fossil fuels as bridge technologies [p1, p2, s1, s2, s3]. Phasing out other, non-coal fossil fuels, including gas, was also mentioned as an objective by some interviewees [p5, s1, s3], as was phasing out coal itself [p2, p6, r6, s3]. The latter, however, was not mentioned very frequently as an objective on its own. The objective of stopping new coal from getting built was mentioned slightly more often [p4, p7, r1, r6, r7]. Several interviewees, however, pointed out that the decision to phase out coal was as a result of various factors, rather than an objective in itself $[\mathrm{b} 1, \mathrm{p} 1$, $\mathrm{p} 4, \mathrm{p} 5, \mathrm{p} 6, \mathrm{p} 7, \mathrm{r} 1, \mathrm{r} 7, \mathrm{~s} 2]$. In line with this, some interviewees emphasized that the UK has a strong preference for market-based instruments to mitigate climate change. Hence, establishing an effective carbon price is another important objective in this category [b1, p6, p7, r2, r5, s1, s4], as well as the broader objective to create market conditions for decarbonization $[\mathrm{b} 1, \mathrm{p} 4, \mathrm{p} 5, \mathrm{r} 5, \mathrm{r} 7$, 
s4]. Shifting the economics away from coal to other energy sources was a key objective as well [b1, p2, p3, p4, p7, r1, r3, s1]. Arguably, certain actors' advocacy for the large-scale use of CCS [p8, r6, s5] can be categorized under this highlevel objective as well, as this technology was meant to reduce GHG emissions. Another notable objective of the UK was to take an international leadership position on climate [p8, r3, r6, s1, s4].

\section{Climate Change Act}

The Climate Change Act in 2008 was a major milestone as it introduced the first binding target of $80 \%$ of emissions reduction by 2050 as compared to the 1990 baseline (Climate Change Act, 2008). It was voted upon almost unanimously in parliament [b2, s4] (Fankhauser et al., 2018) and helped the argument against new built coal [s1]. According to the Climate Change Act, carbon budgets are established every five years [b1, p3, r7, s4]. The Climate Change Act also established the Committee on Climate Change (CCC), an independent advisory body to the government that establishes and monitors carbon budgets and is considered to be very important and influential [p1, p6, r3, s5]. The following Energy Acts of 2011 and 2013 were also mentioned as they established capacity limits on emissions [p3] (Energy Act, 2013). One interviewee pointed out that, while the Climate Change Act set interim climate targets, it did not demand specific technologies and it was the RE targets of the EU that helped establish a priority for RE [p6].Thus far, the UK has been successful in meeting its first two carbon budget targets as obliged by the Climate Change Act. As of 2018 , total GHG emissions in the UK have decreased by $43 \%$ compared to the 1990 baseline. For energy supply, the decrease is even larger at $62 \%$ for the same time period (BEIS, 2020a).

\section{Kingsnorth protests and public opposition to new coal}

Due to the old age of existing coal-fired power stations and the expectation of rising demand [r1] as well as high gas prices [r3], two new coal-fired power stations were proposed around 2008-2009. One of those was by E.ON at the Kingsnorth site in Kent, which was met with mass protests from local movements and NGOs. The protests succeeded in putting pressure onto the then-Labor government so that, as a result, the government eventually ruled out the construction of new unabated coal power stations in April 2009, unabated meaning without CCS. This was the first major policy decision that was directly aimed at coal. As CCS ceased to be a viable option for power plants in the UK, the Kingsnorth decision turned out to be in hindsight, a de facto ban on new coal-fired power stations [r2, r6]. The protests and the subsequent policy decision were considered by several interviewees to have been an important event [r1, r2 r3, r6, s1]. It was also pointed out that stopping Kingsnorth and the other proposed new coal power stations from being built also prevented a lock-in similar to those occurring in other countries, like Germany, which have some relatively new coal-fired power stations [p5, r1, r6, s2]. 
Liberalized and competitive market

The UK's liberalized market structure was a very frequently mentioned context factor. Utilities as well as energy-intensive industries were interested in costeffective investment, generating profits, and gaining or keeping market shares [b1, b2, p2, p4, p5, p6, p7, p8, r1, r4, r5, r6, r7, s1, s2, s3], which influenced their decision for or against coal. Following the EU LCPD in 2001 and later the Industrial Emissions Directive in 2010, the old age of most coal-fired power stations was a major factor in the decision of most operators not to retrofit their plants to meet the new requirements and prepare them for shutdown instead [b2, p2, p5, p8, r1 , r3, r4, r6, r7, s1, s2, s4]. As part of the EMR in 2013, a carbon floor price for the power sector was introduced as a top-up to the EU-ETS, the price of which was considered to be too low to be effective [b1, p2, p4, p5, p6, $\mathrm{p} 7, \mathrm{r} 1, \mathrm{r} 2, \mathrm{r} 5, \mathrm{~s} 1]$. Our interviewees widely considered the carbon floor price to be a major factor in the decline of coal [b1, p5, r2, r3, r4, r5, r7, s1], especially as it was effective in shifting the economics away from coal and in favor of gas [p2, p4, p6, p7, r1]. As one interviewee put it, the UK has an 'institutional love for carbon pricing' [r2]. The carbon price floor further served as a source of revenue for the Treasury and was not solely implemented for climate reasons [p5, p6, r7]. Furthermore, as several interviewees have pointed out, the cost of RE, especially offshore wind, has decreased significantly over the last few years $[\mathrm{b} 2$, p2, r1, r3, r6, s1, s4] (Evans, 2020), whereas, in the early 2000s, they had still been very expensive and had to be subsidized [p2]. As the UK has a large potential for offshore wind $[\mathrm{b} 2, \mathrm{~s} 4]$, it was the cost-effective answer to shift away from coal toward offshore and other RE [p2], which also helped reduce dependency on gas [r6].

\section{Contracts for difference}

The contracts for difference (CFD) scheme was one of the instruments introduced with the EMR of 2013-2014. CFD are large contracts that guarantee fixed electricity prices for new clean energy projects for a certain amount of time and were established to encourage the development of RE generation $[\mathrm{b} 1, \mathrm{p} 1, \mathrm{r} 7]$. Some interviewees emphasized that this scheme has been successful in establishing the offshore wind industry [b1,p3] and it has played a role in the decline of coal [r1]. However, one interviewee criticized that smaller contracts no longer get fixed prices, which discourages small-scale RE projects [p1].

\section{Changing perceptions of CCS}

The option of coal generation with CCS to abate the emissions was in the discussion mainly in the mid-to-late 2000s and some actors expected that the coal industry might transition into CCS at least temporarily [b2, r3, r6]. One argument in favor of CCS was the perceived need for large baseload generators [s1]. The Trade Union Congress (TUC) set up the Clean Coal Task Group in 2006 to make a case for sustaining some coal production with CCS to 
proactively propose a bridge from high to low carbon [r7, s5] (Clean Coal Task Group, 2006). It was debated whether to allow new coal power stations to be built if they were 'CCS ready' [r3]. The NGO community had differing views on the technology. While some NGOs agreed to it under the condition that it was full-scale CCS, others fundamentally rejected it [s1]. The 2009 decision not allowing new coal without CCS, however, made an investment in coal so much more expensive that it led to coal coming off the system entirely rather than utilities investing in CCS [b1, r2, r6, r7]. The government still invested in large-scale CCS demonstration projects, most notably the 'White Rose' project. However, it unexpectedly canceled the project in 2015, which caused anger in the industry and the loss of millions of euros of EU funding [p8, r3, s5] (Carrington, 2015). One interviewee pointed out that the coal industry initially had not invested in CCS at all, and as competition from gas increased, it was no longer economically viable [r6]. As of today, CCS has become uneconomic and is not expected to ever have a significant role in the UK power sector [b2, s1]. Trade unions have also shifted their stance away from CCS, one of the reasons being the residual carbon footprint [s5].

\section{Party leaders' joint pledge on climate}

Another important contextual factor along with the 'climate action' high-level objective is the increasing effort of all three main parties - Conservative, Labor, and Liberal Democrats - to claim some of the UK climate policy space [r3]. In February 2015, ahead of the general election, a group of NGOs and climate think tanks composed a pledge for the three main party leaders, David Cameron, Nick Clegg, and Ed Miliband [p2,r1, r4, r6, r7]. The letter, which was signed by all of them, consisted of three main parts: (1) to work toward a below $-2^{\circ} \mathrm{C}$ compatible global climate deal at COP $21,(2)$ cross-party cooperation on carbon budgets according to the Climate Change Act, and (3) to accelerate the low-carbon transition and end unabated coal generation (Cameron et al., 2015). The letter was a conscious effort of the initiating organizations to create a common position for party leaders and depoliticize the issue of climate change $[\mathrm{r} 4, \mathrm{r} 6, \mathrm{r} 7]$. As reported by some interviewees, the third section on coal phase-out was added only at the last minute at the insistence of some groups, while others did not initially make it a priority [r4, r7]. Especially the role of the Conservative Party was remarkable. The Conservatives had the reputation of not being very environmentally friendly during a time where climate change was increasingly getting to the forefront of voters' minds. In the mid-2000s, the Conservatives wanted to increase their ambition on climate change and include this issue in their election manifesto [p2, p7, r1, r2, $\mathrm{r} 3, \mathrm{r} 7, \mathrm{~s} 1]$. Several interviews mentioned that there was an increasing depoliticization of decarbonization and a political consensus on the need for climate action [b1, p6, r4, r6, r7, s4]. This led to a certain degree of competition among parties so that questions around climate action focused more on the 'how' and not on the 'if'. 
International leadership on climate

Several interviewees mentioned the UK's efforts to position itself as a climate leader [p8, r3, r6, s1, s4], which is also why the UK wanted to increase its ambitions prior to COP 21 in 2015 [r4, r7, s4]. More recently, the objective of leadership on coal phase-out has emerged, such as in the form of the Powering Past Coal Alliance (PPCA) [p2, p7, r4, s4]. With the establishment of the PPCA, the UK aims to use its own record on coal use reduction to encourage similar transitions in other countries (Blondeel et al., 2020). In a broader sense, UK climate leadership ambitions also include international competitiveness and exporting low-carbon technologies such as offshore wind [p4, p5, p6, p7, p8, s1, s4].

\section{Low electricity prices and jobs in the power sector}

The question of how potential negative impacts of low-carbon transitions on the workforce, affected regions, and consumers can be cushioned has gained increasing importance. Cushioning those potential negative effects might also include more active state intervention to replace fossil fuel sectors with green sectors (Healy \& Barry, 2017). The objective to create new jobs and infrastructure and attract low-carbon investment (such as RE and momentarily also CCS) was the most frequently mentioned aspect of the 'low electricity prices and jobs in the power sector' high-level objective [p1, p2, p3, p4, p6, p7, r2, r3, r6, r7, s1, s4, s5]. A close second was to keep consumer electricity prices low [b1, p2, p4, p6, r1, r2, r3, r6, s1, s5]. Other aspects that were mentioned were planning certainty for workers, regions, and companies [p2, p4, p7, r2, r3, s4] and just transitioning for workers, including retraining [b1, b2, s4, s5]. Individual interviewees also mentioned democratization and decentralization of energy [p3] and global justice issues of the fossil-fuel-based system [s3].

\section{Influence of trade unions and the 1984-1985 miners' strike}

Many interviewees stated that the decline of coal actually had its roots already in the 1980s, entirely unrelated to climate change, when the Thatcher government's fight against the coal unions resulted in the closure of hundreds of mines and the weakening of union power [b1, p1, p2, p5, p6, p7, p8, r1, r6, s2, s3, s4, s5]. The government's goal at the time was to break the power of organized labor [p1, s1] (Phillips, 2014). The events following the breakup of the 19841985 miners' strike were very dramatic as the coal mining communities suffered severe economic repercussions that continue to have an effect to this day in terms of weaker social, educational, and health outcomes [p2, r1, r2, s1] (Beatty et al., 2019). The breakup of the union and the massive loss of jobs in the coal industry in a short period of time is generally seen as a negative example of a transition. These negative traumatic experiences are still very present in the UK and there is a strong consensus that future transitions need to be more socially 
cushioned. The UK's domestic coal mining industry is now very small and has little political power $[\mathrm{p} 1, \mathrm{p} 5, \mathrm{p} 6]$. Another effect was the undermining of the political support base for coal [r3].

\section{Job potential of $R E$ and alternative industries}

Some interviewees also mentioned the large job potential in RE, such as offshore wind [p2, s1], and other green sectors, such as retrofitting houses [r4, s4]. One interviewee named the Siemens wind turbine manufacturing plant in Hull as a positive example of just transition as it created several hundred jobs (Vaughan, 2016), some of them for former power plant or coal mine workers [s5]. This project was also said to have played a role in the UK's decision to continue with offshore wind [r7]. However, the regional development aspect must be kept in mind, as the jobs created by green industries are not necessarily in the same places as fossil fuel jobs [s4].

\section{Debate about electricity prices}

There have been public concerns, especially among Conservatives, about rising electricity prices in the early 2010s. A narrative employed especially by the coal industry was that coal would be needed to keep consumer electricity prices low (Brauers et al., 2020) [r6]. There were also concerns about the costs of offshore wind, which were originally perceived to be very high [r3, s1, p2]. However, offshore wind and other renewables became much cheaper in the second half of the decade and this has had a major political impact with respect to the feasibility of the energy transition [p2, r1, r6, s1, s4]. Furthermore, the coal phase-out decision of 2015 has not had a major influence on energy prices (Yilmaz et al., 2016) [p2].

\section{Security of supply}

The high-level objective 'security of supply' was mentioned by many interviewees [b1, p2, p4, p6, p7, p8, r1, r2, r3, r4, r6, r7, s2]. More specifically, a key objective was to meet demand and increase capacity margins, for instance by expanding RE and increasing overall electricity supply [b2, p3, p5, p6, r1, $\mathrm{r} 3, \mathrm{r} 4]$. Several interviewees also mentioned the objective of utilizing gas as a transition fuel to replace coal [b2, p2, p4, p7, r1, r2, r5, r7, s1, s4]. Closely related are issues of grid management and electricity mix, such as ensuring system stability and flexibility with higher shares of RE or ensuring baseload [b1, b2, p3, $\mathrm{p} 4, \mathrm{r} 2, \mathrm{r} 4, \mathrm{r} 6, \mathrm{r} 7, \mathrm{~s} 4]$.

\section{Declining energy demand}

An important contextual factor along with the high-level objective 'security of supply' is that, in the 2000-2010 decade, the assumption was that electricity 
demand would keep rising [r1, r3]. However, this has not been the case and demand has actually been falling [r1, r3, r7]. In 2005, final users consumed 349.35 TWh of electricity. By 2019, this number had decreased to $295.48 \mathrm{TWh}$ (BEIS, 2020c), increasing the competition between remaining fossil-fueled electricity providers. The two main reasons for demand reduction as stated by interviewees were the shift from heavy industry to high-value manufacturing and services that occurred mainly in the 1990s and 2000s [r1, r3], as well as better energy efficiency of lighting and white goods, which was partly due to the EU Ecodesign Directive, as well as industrial energy efficiency [r1, r3, r7] (Evans, 2019).

\section{Reporting of capacity margins}

As some interviewees mentioned, there were significant concerns about future energy security due to the tightness of capacity margins in electricity, which also affected the coal phase-out debate [p2, p3, p6, p7]. However, as one interviewee pointed out, it turned out later that the capacity gap was not as small as initially thought, which was due to the way the tightness of margins was reported. Since visibility was only at a very high level, many capacity additions from onshore wind and solar were not measured. Based on this perceived tightness of capacity margins, government ministers wanted to keep some coal in the system to avoid security of supply issues [p3]. Security of supply concerns was the main reason for the establishment of the CM.

\section{Capacity market}

The CM was also part of the EMR and includes payments for generators for standing ready as well as additional payments if they actually provide supply [p3]. It was designed with the aim of encouraging the construction of new gas power stations to compensate for coal and thus ensure security of supply [b1, p6, r7]. Opinions on the effectiveness of the CM differed among interviewees. Some interviewees stated that it has generally been successful [b2, p4]. Others criticized that the CM initially had no carbon intensity limitations, which meant that coal power plants could get long-term contracts under certain circumstances [p3, r2, r7, s1]. Some interviewees argue that the CM has slowed the coal phase-out and kept some coal power plants on the system longer than they would have otherwise [b1, p3, r2]. The number of CM agreements for coal power stations has since decreased and it is expected to get to zero in future auctions [p4].

\section{Discussion}

To summarize, the phase-out of coal-fired power generation in the UK appears to be very successful for a number of reasons. First of all, there are several context factors that have led to low political stakes in coal. Furthermore, there is 
a high political consensus on climate change across the major parties, which enabled effective climate policies. More recently, the change in the perception of the CCS technology has further ruled out coal as a viable source of future electricity.

While the demise of coal seems inevitable, it is not entirely clear where the UK energy system is headed as a whole, as RE compete with nuclear and gas. Although barely mentioned in our interviews, it is important to note that the Hinkley Point $\mathrm{C}$ nuclear power station is currently under construction. The project is highly controversial; studies have found that it would have been more cost-efficient for the UK to invest in RE than in nuclear (Johnstone et al., 2017; Schneider et al., 2020; Suna \& Resch, 2016). Further challenges arise with respect to gas, which needs to be phased out or decarbonized in order to meet the net zero target. There have been intense debates about the extraction of shale gas, which has been favored by governments but faces major public opposition (Bomberg, 2017; Johnstone et al., 2017). Increasing shares of RE have played a significant role in covering the UK's electricity demand. However, during the study period 2000-2020, government support for RE has varied substantially. Financial support for RE, especially through feed-in tariffs, has declined, which especially affected the solar industry and has hindered the development of solar energy in the UK (George, 2020).

It will also be interesting to see how the Conservatives position themselves in the future with regard to climate protection policies. As mentioned above, they have been speaking out more strongly for climate protection since the middle of the 2000s, but their policies have not always been in accordance with this. For example, when a Conservative majority government was elected in 2015, many environmental policies were stopped initially [p7, r7] (Vaughan \& Macalister, 2015). However, by 2015, the majority of Conservative MPs were in favor of the coal phase-out, which became part of their election manifesto in the shape of the aforementioned cross-party climate agreement [p2]. The final decision to phase out coal was therefore, as mentioned by some interviewees, a measure to strengthen their climate credentials $[\mathrm{p} 7, \mathrm{r} 2, \mathrm{r} 7]$.

As the UK is one of the first countries to have nearly completed the transition away from coal power generation over a relatively short period of time, the question that suggests itself is whether other countries can derive lessons from the UK's coal phase-out experience. Several interviewees stressed that every country and market is different and there is no 'one-size-fits-all' type of solution [b2, r1, r3, s1]. What was pointed out frequently is that, in countries with a strong domestic mining industry, like Germany or Poland, regional and employment aspects add an additional layer of complexity that was not as prominent in the UK in the 21st century [p2, p6, p7, p8, r1, r2, r3].

What was also mentioned frequently was the effectiveness of creating appropriate market conditions for decarbonization [b1, p3, r2], particularly strong carbon pricing for the power sector [p2, p5, p6, p7, r3, r7, s1]. However, as many 
interviewees have emphasized, carbon pricing is not a stand-alone solution but should rather be one component of a policy mix that is tailored to the country's individual circumstances [p4, p6, p7, r3, r4, s1]. The need for accompanying policies to support investment in low-carbon energy was mentioned frequently to replace phased out coal capacity [p1, p5, p6, p7, r4, s1, s4].

\section{Conclusions and outlook}

The UK has almost completed its phase-out of coal generation over a relatively short period of time. In the 2000s, at the beginning of our study period, coal's share of the UK electricity mix was at a relatively constant rate at around $27 \%-37 \%$. Starting in 2013 , its share began to shrink rapidly to merely $1.74 \%$ in 2020. As part of this, by 2020, overall GHG emissions of the UK have been reduced by 48.8\% compared to 1990 (BEIS, 2021b). This chapter identifies objectives, actors, and contextual factors of the UK coal phase-out using the AOC Framework by Jakob et al. (2020). From our evaluation of 22 stakeholder interviews, we derived 3 high-level objectives that have influenced the UK case: (1) climate action, (2) low electricity prices and jobs in the power sector, and (3) security of supply.

The UK coal phase-out has been enabled by a variety of policies and contextual factors. Notable policies include effective carbon pricing and support for the RE industry. Climate ambitions in all three major political parties, the importance of scientific advice and the avoidance of political polarization on the issue played a major role as well. Security of supply issues didn't become a major problem as inter alia electricity demand - other than expected - was falling considerably. The coal-fired power stations in the UK were old, and the civil society protests, especially in Kingsnorth, prevented the construction of new power stations in the 2000s. Unlike in other countries, like Germany (Brauers et al., 2020; Oei et al., 2019), the coal companies did not use their political power to slow down the decision to phase out coal because they had little to lose. They decided early on to invest in other energy sources. The official announcement to phase out coal that was made in 2015 is widely considered to be merely a formalization of something that would have happened anyway due to the preceding developments and policies that have shifted the economics away from coal.

As a more recent development, in 2019, the UK has legislated for net zero emissions by 2050 due to the scientific evidence of the IPCC $1.5^{\circ} \mathrm{C}$ report and the CCC, as well as public pressure from climate movements. However, this is unlikely to have any significant further impact on the coal phase-out, which is already well underway. Instead, future challenges for the UK are related to natural gas, especially with respect to heating, as well as the future of transportation. In summer 2020, the UK experienced a coal-free run for 67 days, which was only interrupted for maintenance purposes of a coal power station (National Grid ESO, 2020). Much like in many other countries, the Covid-19 pandemic 
further raises the issue of how to achieve a climate-friendly economic recovery post Covid in the UK.

\section{Acknowledgments}

We would like to thank all interviewees for their valuable contribution that has made this study possible, as well as the participants of the Political Economy of Coal workshops hosted by MCC Berlin and the participants of the colloquium at the CoalExit research group for their useful discussions and suggestions. We would further thank two anonymous reviewers for their helpful comments on the manuscript, which have greatly contributed to improving this chapter. This work was supported by the German Ministry of Education and Research (BMBF) under grant number 01LN1704A ('CoalExit' project) and under grant number 01LA1810A ('Future of Fossil Fuels in the Wake of Greenhouse Gas Neutrality' project). Paula Walk gratefully acknowledges funding from the Heinrich Böll Foundation.

\section{Appendix}

This chapter contains supplementary online material at www.mcc-berlin.net/ pecoal/ch05.

\section{Notes}

1 Kilroot power station is going to be converted to gas by winter 2023 and West Burton does not hold a capacity market contract for winter 2021-2022. Ratcliffe and Drax do hold capacity market contracts for that period, but the latter has ceased coal generation and only keeps its coal capacity on standby (Evans, 2021). In line with the coal phase-out announcement, Ratcliffe power station will have to close by 2024 as well.

2 Please note that we were only able to conduct two interviews with business officials, a number that is too small to constitute a representative sample.

3 Gas in the UK was and often is also still cheaper than in many other European countries due to the availability of domestic production (Brauers et al., 2020).

\section{References}

Beatty, C., Fothergill, S., \& Gore, T. (2019). The State of the Coalfields 2019. Economic and social conditions in the former coalfields of England, Scotland and Wales [A report commissioned by the Coalfields Regeneration Trust]. Sheffield Hallam University, Centre for Regional Economic and Social Research. www4.shu.ac.uk/research/ cresr/sites/shu.ac.uk/files/state-of-the-coalfields-2019.pdf

BEIS. (2020a). 2018 UK Greenhouse Gas Emissions, Final figures (National Statistics). Department for Business, Energy \& Industrial Strategy. https://assets.publishing.service.gov.uk/government/uploads/system/uploads/attachment_data/file/862887/ 2018_Final_greenhouse_gas_emissions_statistical_release.pdf 
BEIS. (2020b). End of Coal Power to be Brought Forward in Drive Towards Net Zero [Press release]. Department for Business, Energy \& Industrial Strategy. www.gov.uk/government/news/end-of-coal-power-to-be-brought-forward-in-drive-towards-net-zero

BEIS. (2020c). Historical Electricity Data: 1920 to 2019. www.gov.uk/government/ statistical-data-sets/historical-electricity-data

BEIS. (2021a, March 25). Energy Trends: UK electricity. National Statistics. www.gov.uk/ government/statistics/electricity-section-5-energy-trends

BEIS. (2021b). Provisional UK Greenhouse Gas Emissions National Statistics 2020 (National Statistics).Department for Business, Energy \& Industrial Strategy.www.gov.uk/government/statistics/provisional-uk-greenhouse-gas-emissions-national-statistics-2020

Blondeel, M.,Van de Graaf,T., \& Haesebrouck,T. (2020). Moving beyond coal: Exploring and explaining the Powering Past Coal Alliance. Energy Research \& Social Science, 59, 101304. https://doi.org/10.1016/j.erss.2019.101304

Bomberg, E. (2017). Shale we drill? Discourse dynamics in UK fracking debates. Journal of Environmental Policy \& Planning, 19(1), 72-88. https://doi.org/10.1080/ 1523908X.2015.1053111

Brauers, H., Oei, P.-Y., \& Walk, P. (2020). Comparing coal phase-out pathways: The United Kingdom's and Germany's diverging transitions. Environmental Innovation and Societal Transitions, 37, 238-253. https://doi.org/10.1016/j.eist.2020.09.001

Carrington, D. (2015, November 25). UK cancels pioneering $\mathcal{E}_{1} 1 \mathrm{bn}$ carbon capture and storage competition. The Guardian. www.theguardian.com/environment/2015/ nov/25/uk-cancels-pioneering-1bn-carbon-capture-and-storage-competition

Clean Coal Task Group. (2006). A Framework for Clean Coal in Britain. www.tuc.org.uk/ research-analysis/reports/framework-clean-coal-britain

Climate Change Act, C. 27 (2008). www.legislation.gov.uk/ukpga/2008/27/pdfs/ ukpga_20080027_en.pdf

Energy Act, C. 32 (2013). www.legislation.gov.uk/ukpga/2013/32/pdfs/ukpga_ 20130032_en.pdf

Evans, S. (2019, January 3).Analysis: UK electricity generation in 2018 falls to lowest level since 1994. Carbon Brief. www.carbonbrief.org/analysis-uk-electricity-generation2018-falls-to-lowest-since-1994

Evans, S. (2020, August 27). Wind and solar are 30-50\% cheaper than thought, admits UK government. CarbonBrief. www.carbonbrief.org/wind-and-solar-are30-50-cheaper-than-thought-admits-uk-government

Evans, S. (2021, March 12). Countdown to 2025:Tracking the UK coal phase out. Carbon Brief. www.carbonbrief.org/countdown-to-2025-tracking-the-uk-coal-phase-out

Fankhauser, S., Averchenkova, A., \& Finnegan, J. (2018). 10 Years of the UK Climate Change Act. Grantham Research Institute on Climate Change and the Environment. www.lse.ac.uk/GranthamInstitute/wp-content/uploads/2018/03/10-Years-of-theUK-Climate-Change-Act_Fankhauser-et-al.pdf

Geels, F. W., Kern, F., Fuchs, G., Hinderer, N., Kungl, G., Mylan, J., Neukirch, M., \& Wassermann, S. (2016). The enactment of socio-technical transition pathways: A reformulated typology and a comparative multi-level analysis of the German and UK low-carbon electricity transitions (1990-2014). Research Policy, 45(4), 896-913. https://doi.org/10.1016/j.respol.2016.01.015

George, S. (2020, March 31). One year on: How has the solar feed-in-tariff closure impacted renewables in the UK? Edie Newsroom. www.edie.net/news/10/ One-year-on--What-impact-has-the-solar-feed-in-tariff-closure-had-in-the-UK-/ 
Grubb, M., \& Newbery, D. (2018). UK electricity market reform and the energy transition: Emerging lessons. The Energy Journal, 39(01), 1-26. https://doi.org/10.5547/ 01956574.39.6.mgru

Healy, N., \& Barry, J. (2017). Politicizing energy justice and energy system transitions: Fossil fuel divestment and a "just transition." Energy Policy, 108, 451-459. https://doi.org/10.1016/j.enpol.2017.06.014

Isoaho, K., \& Markard, J. (2020). The politics of technology decline: Discursive struggles over coal phase-out in the UK. Review of Policy Research, ropr.12370. https://doi.org/ 10.1111/ropr.12370

Jakob, M., Flachsland, C., Steckel, J. C., \& Urpelainen, J. (2020). Actors, objectives, context: A framework of the political economy of energy and climate policy applied to India, Indonesia, and Vietnam. Energy Research \& Social Science, 70, 101775. https:// doi.org/10.1016/j.erss.2020.101775

Johnstone, P., Stirling,A., \& Sovacool, B. (2017). Policy mixes for incumbency: Exploring the destructive recreation of renewable energy, shale gas 'fracking,' and nuclear power in the United Kingdom. Energy Research \& Social Science, 33, 147-162. https://doi. org/10.1016/j.erss.2017.09.005

Littlecott, C. (2015). G7 Coal Phase-Out: United Kingdom [A Review for Oxfam]. E3G. www.jstor.com/stable/resrep17748

Littlecott, C., Burrows, L., \& Skillings, S. (2018). Insights from the UK Coal Phase Out Experience [Report to Chile Decarbonisation Roundtable]. E3G.

Michaels, C. (2016). Coal in 2015 (Energy Trends) [Special feature article]. Department for Business, Energy \& Industrial Strategy (BEIS). https://assets.publishing.service. gov.uk/government/uploads/system/uploads/attachment_data/file/559575/Coal_ in_2015.pdf

National Grid ESO. (2020, June 17). Twitter. https://twitter.com/ng_eso/status/ 1273170519702020096

Oei, P.-Y., Brauers, H., \& Herpich, P. (2019). Lessons from Germany's hard coal mining phase-out: Policies and transition from 1950 to 2018. Climate Policy, 1-17. https:// doi.org/10.1080/14693062.2019.1688636

Phillips, J. (2014). Containing, isolating, and defeating the miners: The UK Cabinet Ministerial Group on Coal and the three phases of the 1984-85 strike. Historical Studies in Industrial Relations, 35, 117-141.

Rudd, A. (2015, November 18). Amber Rudd's Speech on a New Direction for UK Energy Policy. www.gov.uk/government/speeches/amber-rudds-speech-on-a-newdirection-for-uk-energy-policy

Schneider, M., Froggatt, A., Hazemann, J., Wealer, B., Ahmad, A., Stienne, A., Katsuta, T., Meinass, F., \& Ramana, M.V. (2020). World Nuclear Industry Status Report 2020. www. worldnuclearreport.org/IMG/pdf/wnisr2020_lr.pdf

Steckel, J. C., Edenhofer, O., \& Jakob, M. (2015). Drivers for the renaissance of coal. Proceedings of the National Academy of Sciences, 112(29), E3775-E3781. https://doi. org/10.1073/pnas.1422722112

Suna, D., \& Resch, G. (2016). Is nuclear economical in comparison to renewables? Energy Policy, 98, 199-209. https://doi.org/10.1016/j.enpol.2016.08.023

van der Burg, L. (2017). Cutting Europe's Lifelines to Coal: Tracking Subsidies in 10 Countries. ODI Country Brief: United Kingdom. Overseas Development Institute.

Vaughan, A. (2016, December 1). Hull's Siemens factory produces first batch of wind turbine blades. The Guardian. www.theguardian.com/business/2016/dec/01/ hull-siemens-factory-wind-turbine-blades 
Vaughan, A., \& Macalister, T. (2015, July 24). The nine green policies killed off by the Tory government. The Guardian. www.theguardian.com/environment/2015/jul/ 24/the-9-green-policies-killed-off-by-tory-government

Yilmaz, H. Ü., Bchini, Q., Keles, D., Hartel, R., Fichtner, W., Mikulić, M., \& Jakšić, D. (2016). Impacts of a UK and German Coal Phase-Out on the Electricity Mix and $\mathrm{CO}_{2}$ Emissions in Europe (No. 14; Hot Energy Topic). INSIGHT_E. https://publikationen. bibliothek.kit.edu/1000087888 